\title{
EFFECT OF DIFFERENT TEMPERING TEMPERATURES ON MECHANICAL PROPERTIES AND MICROSTRUCTURE OF MARTENSITIC STAINLESS STEEL
}

\author{
RAJENDRA. P $^{1^{*}}$, PRADEEP KUMAR. K V $\mathbf{V}^{2}$, DR. SUNITHBABU. $\mathbf{L}^{3}$ \\ ${ }^{1,2}$ Assistant Professor, Department of Mechanical Engineering, Ramaiah Institute of Technology Bengaluru, Karnataka, India \\ ${ }^{3}$ Associate Professor, Department of Mechanical Engineering, Ramaiah Institute of Technology Bengaluru, Karnataka, India
}

\begin{abstract}
The alloy steels are extensively used in every industry ranging from household utensils to the aerospace industry. This research work mainly focuses on the evaluation of the mechanical properties of martensitic stainless steel SS410 \& SS420 materials subjected to tempering heat treatment process by various levels of temperature. Most of the martensitic steel is subjected to the tempering process to vary the mechanical properties like ductility \& toughness is required for most of the applications varying from household utensils to the aerospace industry. Steel properties can vary to a great extent with even a small change in its chemical composition and temperature. The martensitic stainless steels SS410 \& SS420 are subject to microstructure examination and the mechanical properties like hardness, tensile, and impact strength are evaluated for each specimen. The results are then compared with the untreated and heat-treated martensitic stainless steels SS410 \& SS420 for the change in its microstructure and mechanical properties.
\end{abstract}

KEYWORDS: Martensitic Stainless Steel, Tempering, Microstructure Examination, Hardness, Tensile test \& Impact test

Received: May 29, 2020; Accepted: Jun 19, 2020; Published: Jun 30, 2020; Paper Id.: IJMPERDJUN2020257

\section{INTRODUCTION}

Stainless Steel is a class of material that consists of two basic elements namely carbon and iron followed by many other secondary elements, it is extensively used in construction industry due to its high tensile strength and availability [1]. Steel is available in two crystalline forms namely (Body Centered Cubic and FaceCentered Cubic) as it is temperature dependant. The percentage of carbon can vary up-to $2.1 \%$ of its weight. Due to percentage variation, carbon is available in steel either as a solute or in precipitated form $[2,3]$. Iron becomes ductile due to the dislocations this in turn controls the mechanical properties such as hardness, ductility, impact and tensile strength [4].

Stainless steel can be classified based on the alloying constituents which in turn controls the microstructure $[5,6]$. Among the stainless steels, Austenitic type areweldable and extensively used in different industrial applications, not limited to food and chemical industries. They have a face-centered cubic structure [7].

Body Centered Cubic structure is observed in iron chromium alloys of Ferrite Stainless Steels [8, 9]. These steels are ductile and formable, however at elevated temperature their strength reduces. Some ferritic stainless steel are used in automotive, household and consumer applications [10]. Martensitic stainless steels also comprise of Ni, $\mathrm{C}$, Mo, and $\mathrm{Cr}$ likely in composition with the ferrite group[11]. The austenitic structure is stable at elevated temperatures whereas the Martensitic structure is stable at room temperature. The sudden quenching is the only method to form martensitic crystal structure and this structure having high hardness, brittleness, and strength [12]. 
These properties are not suitable for structural applications. Hence, the ductility and toughness of the martensitic material can be improvised by the heat-treatment process. By varying the chemical composition, the mechanical properties can be enhanced [13-14], controlling microstructure, and subjected to the heat-treatment process. Tempering is necessary to enhance the machinability, refine grain size, refine grain structure, and relieve the internal stressesand which in turn increases ductility [14].

\section{MATERIAL AND METHODS}

\subsection{Materials}

The SS410 is a heat treatable martensitic chromium stainless steel. To develop a defect-free surface, melting practice is controlled. SS410 provides an excellent combination of wear corrosion resistance. It is also used in demanding medicalaccessories.

Table 1: Chemical Composition of SS410

\begin{tabular}{|c|c|c|c|c|c|c|}
\hline Element & $\mathbf{C}$ & Si & Mn & P & S & Cr \\
\hline Composition in\% & 00.128 & 00.581 & 00.675 & 00.039 & 00.031 & 12.591 \\
\hline
\end{tabular}

SS420 Stainless steels comprises of various versions of grade 420 containing molybdenum, vanadium and sulphur, it also consists of grades of SS440. Martensitic stainless steels contain high carbon which leads to higher hardness. These steels are hardened and tempered during fabrication. At elevated temperature, these steels lose mechanical strength and at sub-zero temperatures, reduces ductility. This temperature dependence of Martensitic steels affects its operating conditions.

Table 2: Chemical Composition of SS410

\begin{tabular}{|c|c|c|c|c|c|c|}
\hline Element & $\mathbf{C}$ & $\mathbf{S i}$ & $\mathbf{M n}$ & $\mathbf{P}$ & $\mathbf{S}$ & $\mathbf{C r}$ \\
\hline Composition in\% & 00.185 & 00.566 & 00.704 & 00.026 & 00.029 & 12.485 \\
\hline
\end{tabular}

\subsection{Preparationof Test Specimen}

Sets of test specimens were prepared for Hardness, Tensile, Impact, and Microstructural analysis. The following Table 3 shows standards used required to conduct the various tests.

Table 3: Standards used for Tests

\begin{tabular}{|c|c|}
\hline Test Name & Test Standards \\
\hline TensileTest & ASTME-8 \\
\hline CharpyTest & BIS-1499 \\
\hline
\end{tabular}




\subsection{Methodology}

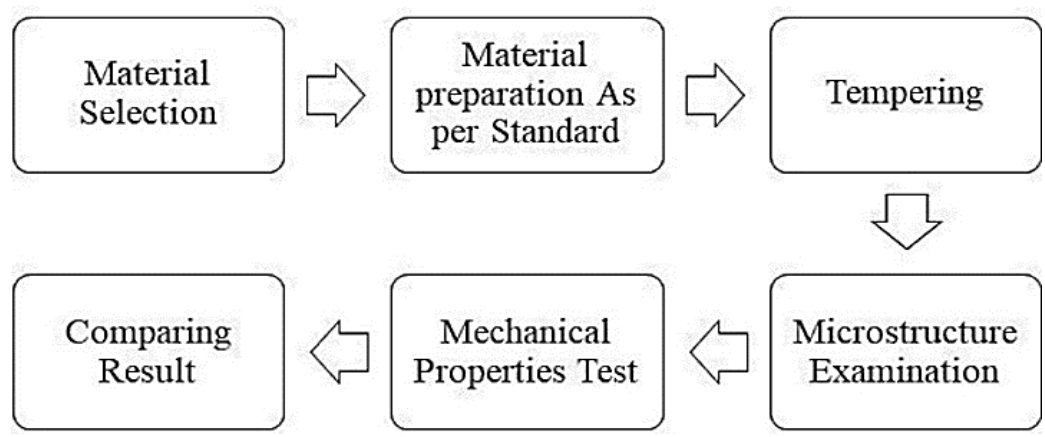

Chart 1: Methodology Procedure.

Samples of SS410 and SS420 are selected for experimentation. Chemical composition and microstructure of the samples are found out respectively then Samples are forged at $900^{\circ} \mathrm{c}$ as shown in Figure 1 at 4 ton followed by oil soaking for one hour to impart hardness.

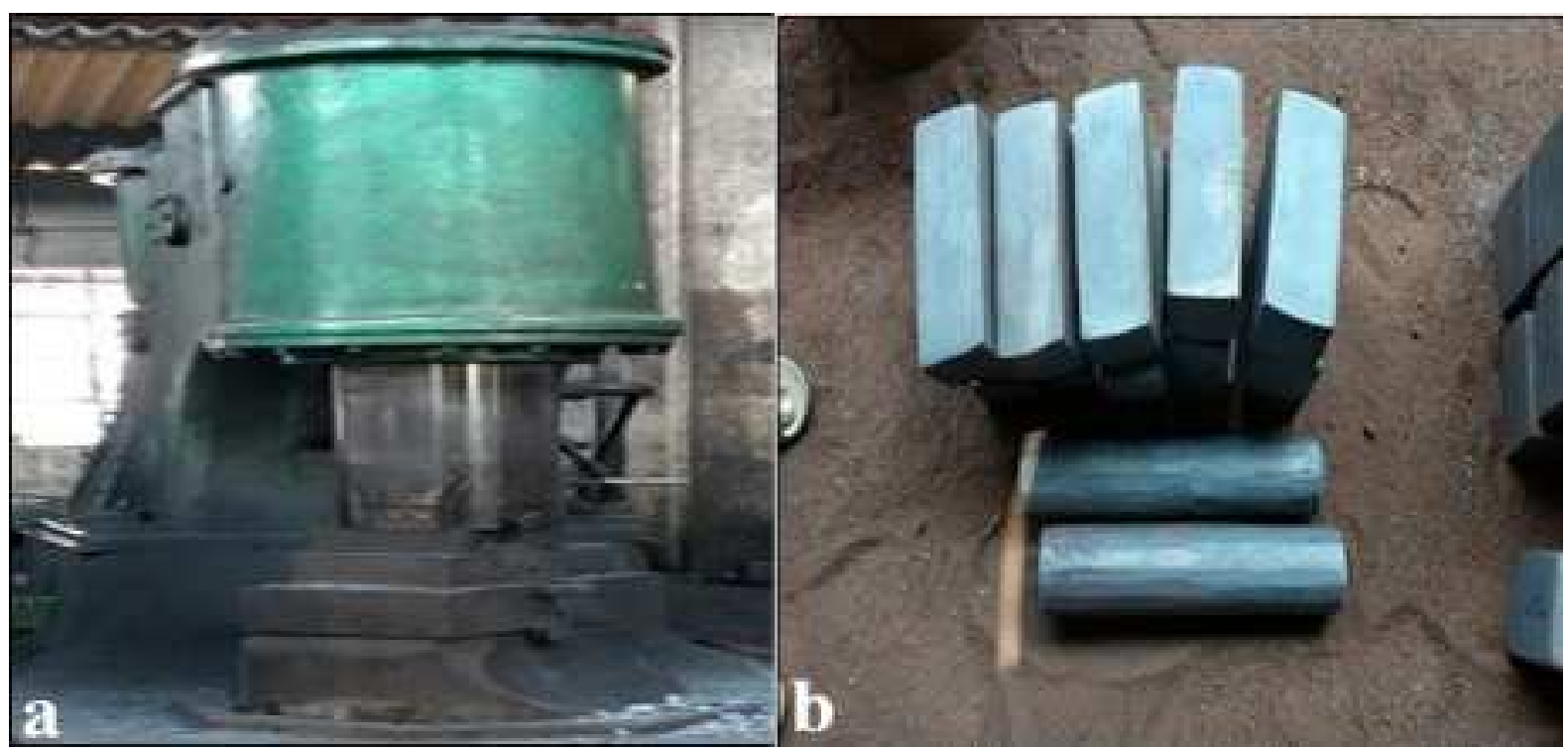

Figure 1(a): Forging Machine

Figure 1 (b): Forging Samples 


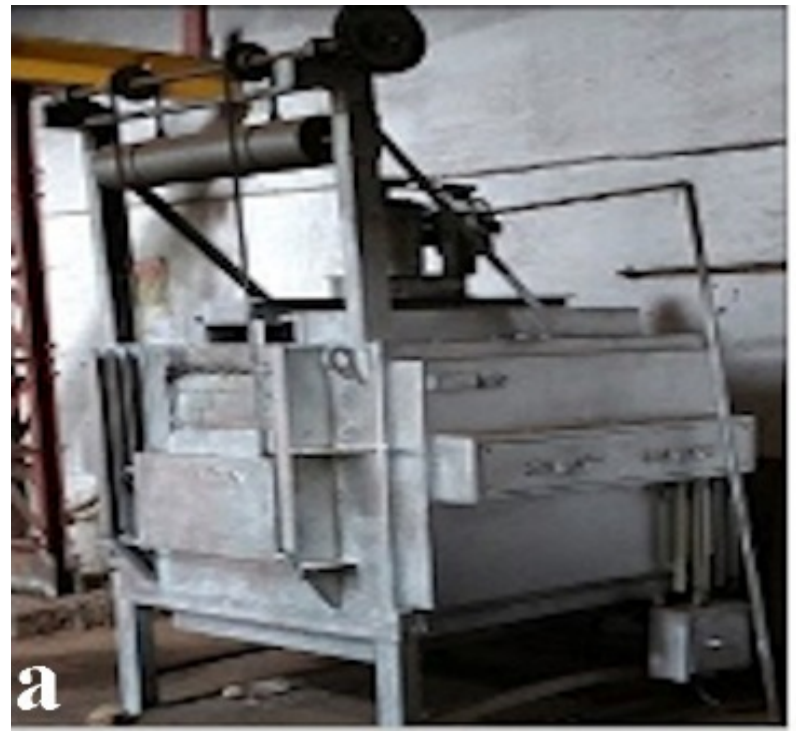

Figure 2(a): Electrical Furnace

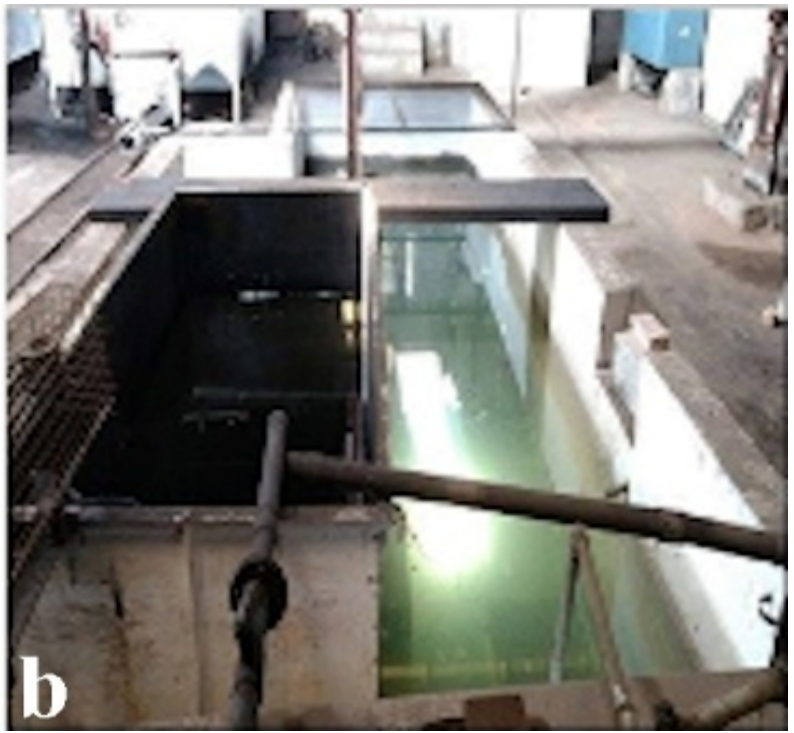

Figure 2(b): Oil Soaking Tank

The Electrical Furnace Capacity is $2000 \mathrm{~kg}$ load, Temperature $800^{\circ} \mathrm{c}$ and $1000^{\circ} \mathrm{c}$ and Size $2050 \times 1860 \times 1480$ $(\mathrm{D} \times \mathrm{W} \times \mathrm{H})$ as shown in Figure 2. The samples are oil quenched at $980^{\circ} \mathrm{C}$. These Samples are tempered at different temperatures i.e. $300^{\circ} \mathrm{c}, 400^{\circ} \mathrm{c}, 500^{\circ} \mathrm{c}, 600^{\circ} \mathrm{c}, 700^{\circ} \mathrm{c}$ and $800^{\circ} \mathrm{c}$ respectively. Microstructure of the tempered samples are studied and compared to the original samples. Tempered samples are further machined to prepare test specimens as shown in Figure 4 and testing machines for tensile test and impact test as show in Figure 3.

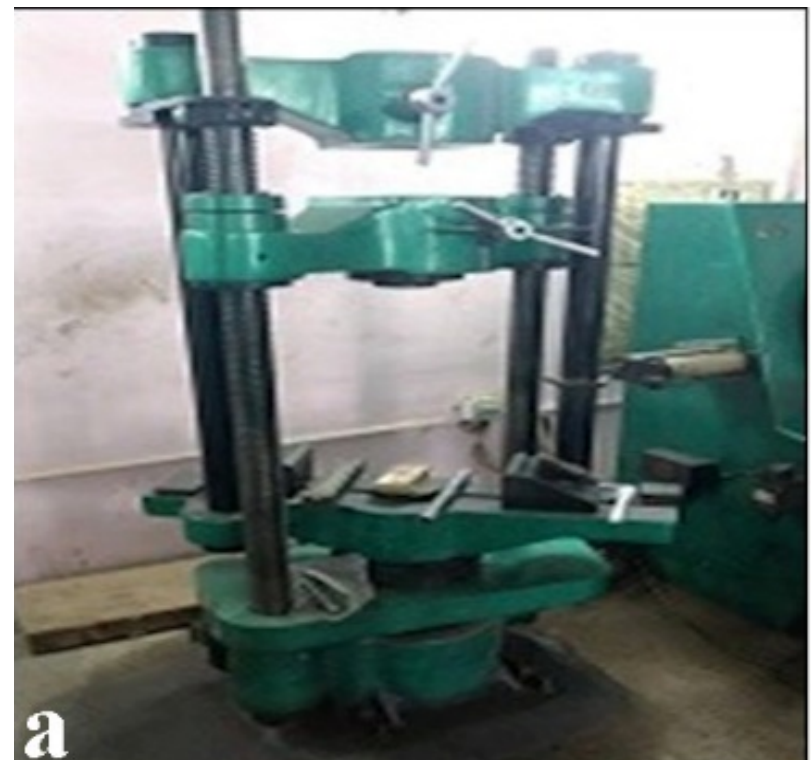

Figure3 (a): Tensile Testing Machine

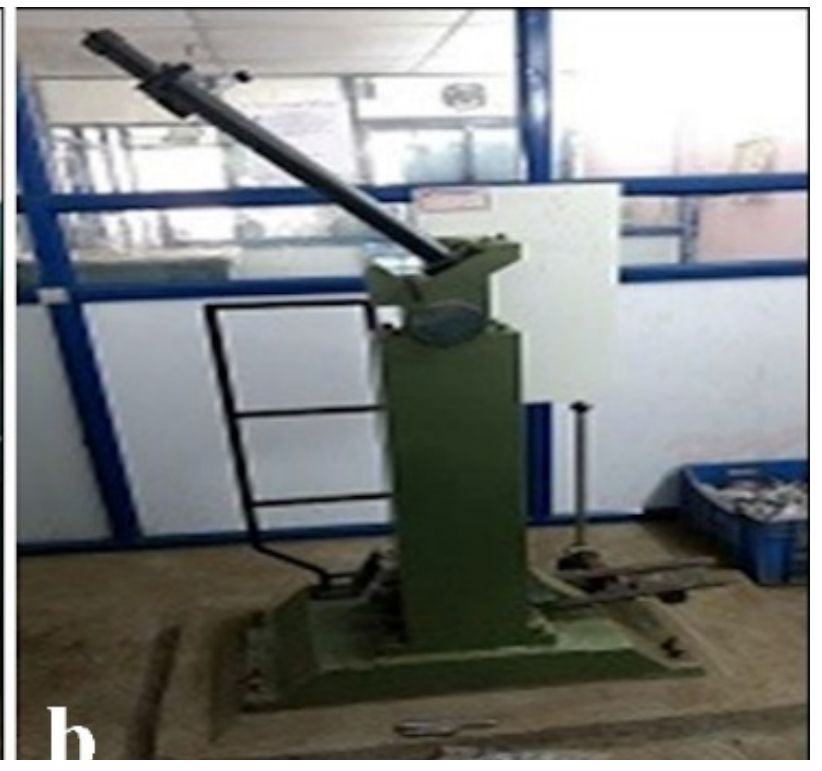

Figure 3(b): Impact Testing Machine 


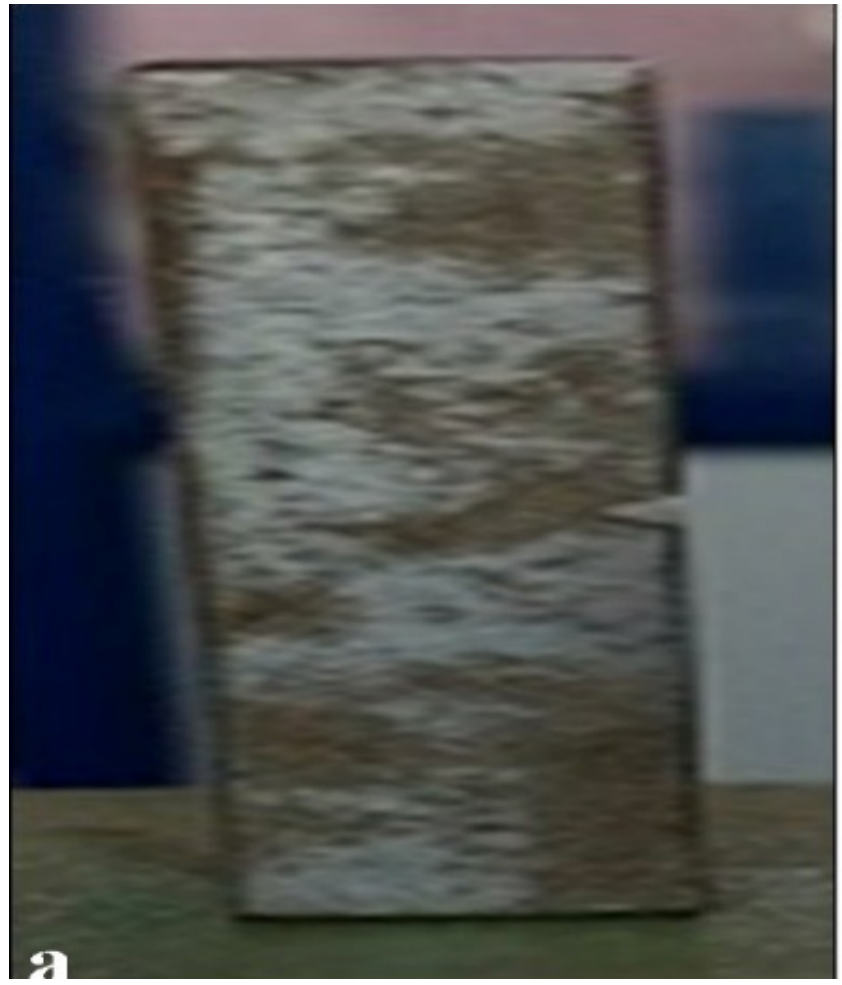

Figure 4(a): Impact Testing Specimen

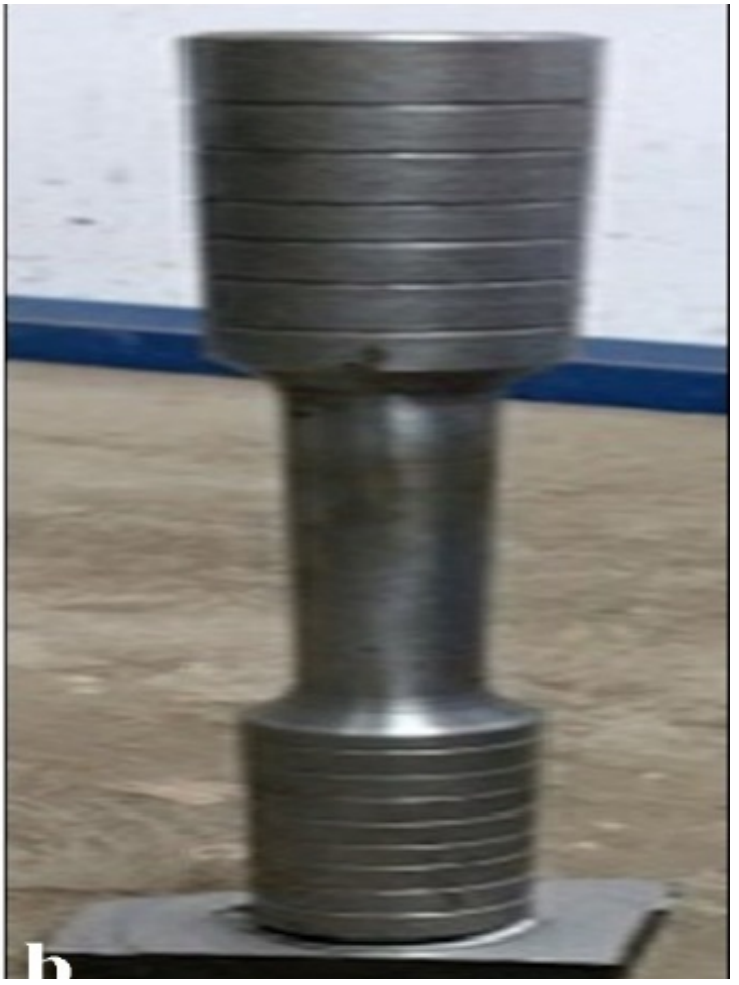

Figure 4(b): TensileTesting Specimen

\section{RESULT AND DISCUSSIONS}

\subsection{Microstructure Examination}

Optical metallurgical microscope (Model: Nikon epiphot 200) is used for microstructure examination of SS410 and SS420 material at various tempering temperatures. The microstructure examination is carried out at a magnification of $50 \mu \mathrm{m}$. The Figure 5 and Figure 6as shown, it clearly shows the presence of fine needle type martensitic microstructure before tempering heat treatment process.

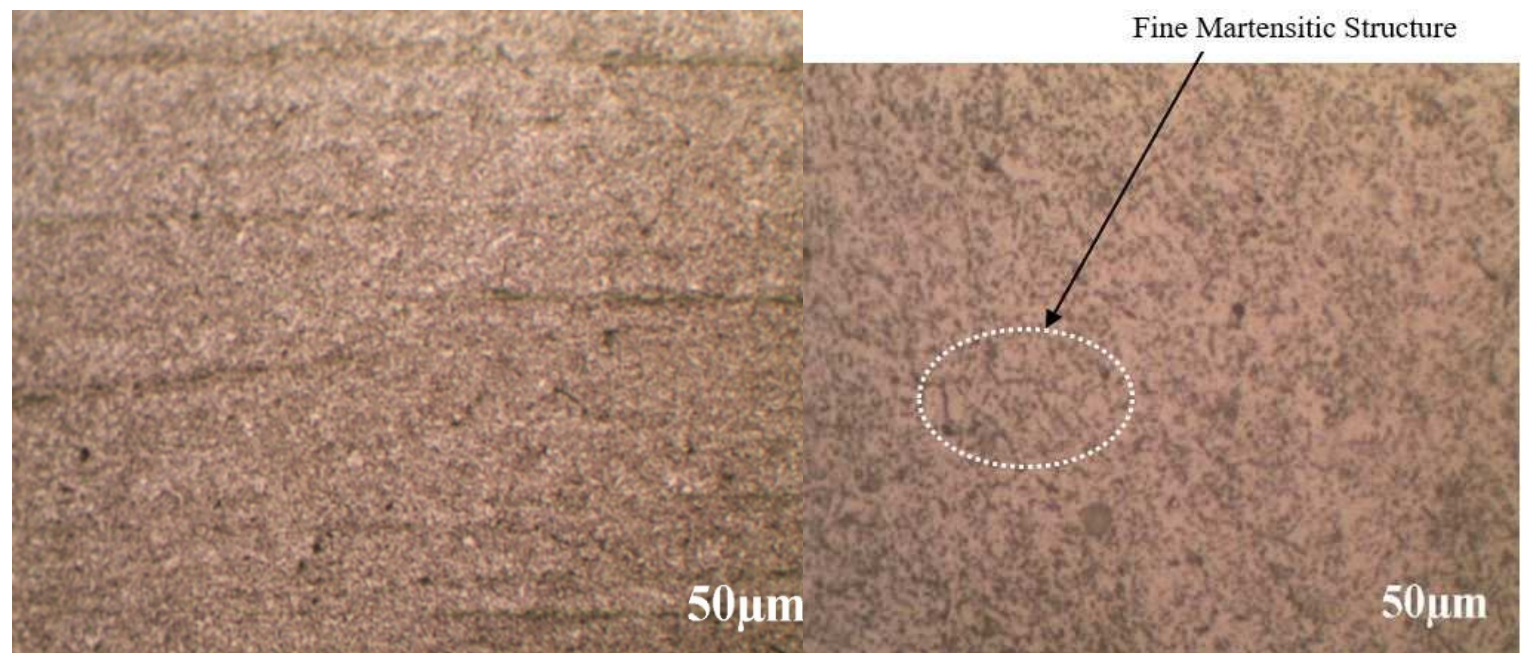

Figure 5: Microstructure of SS410 Martensitic Material Figure 6: Microstructure of SS420 Martensitic Material 


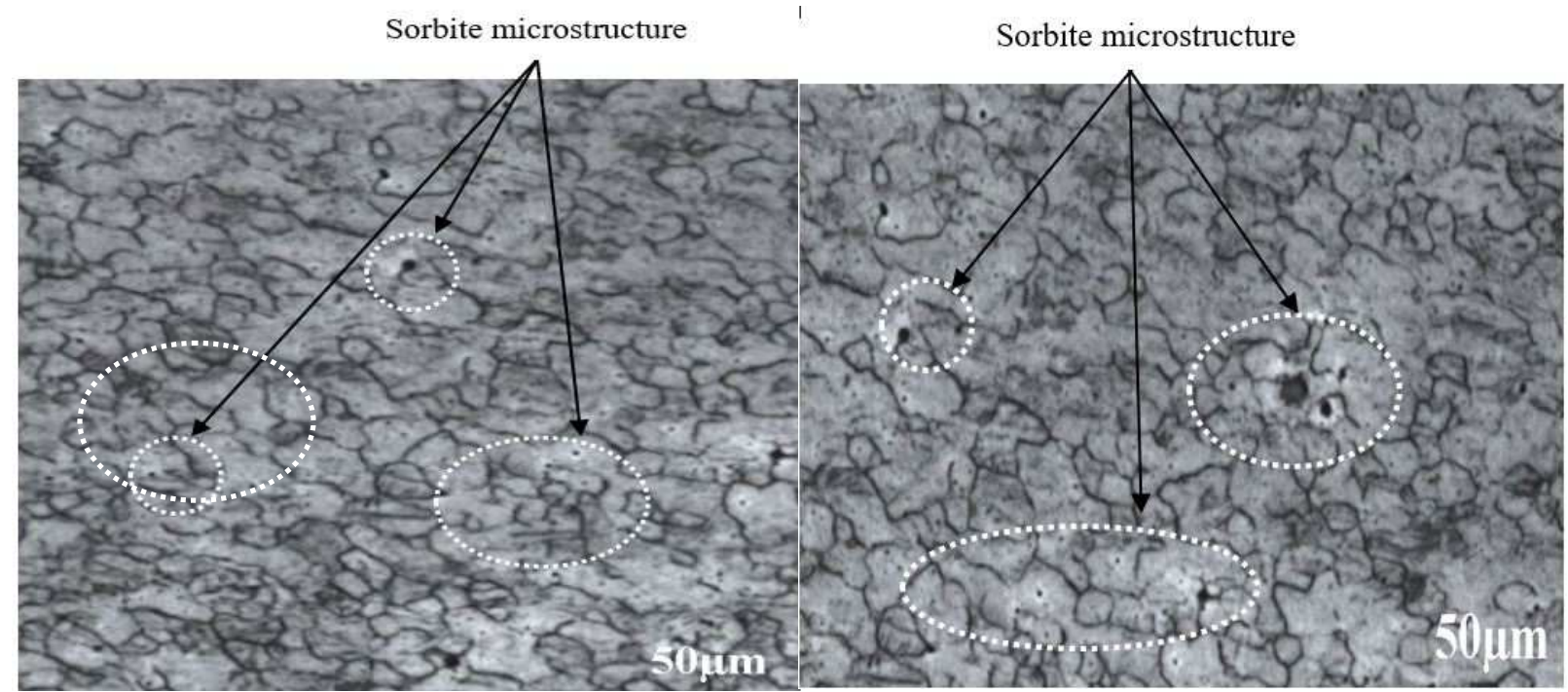

Figure 7: Microstructure of Tempered Samples at $300^{\circ} \mathrm{c}$ Figure 8: Microstructure of Tempered Samples at $400^{\circ} \mathrm{c}$

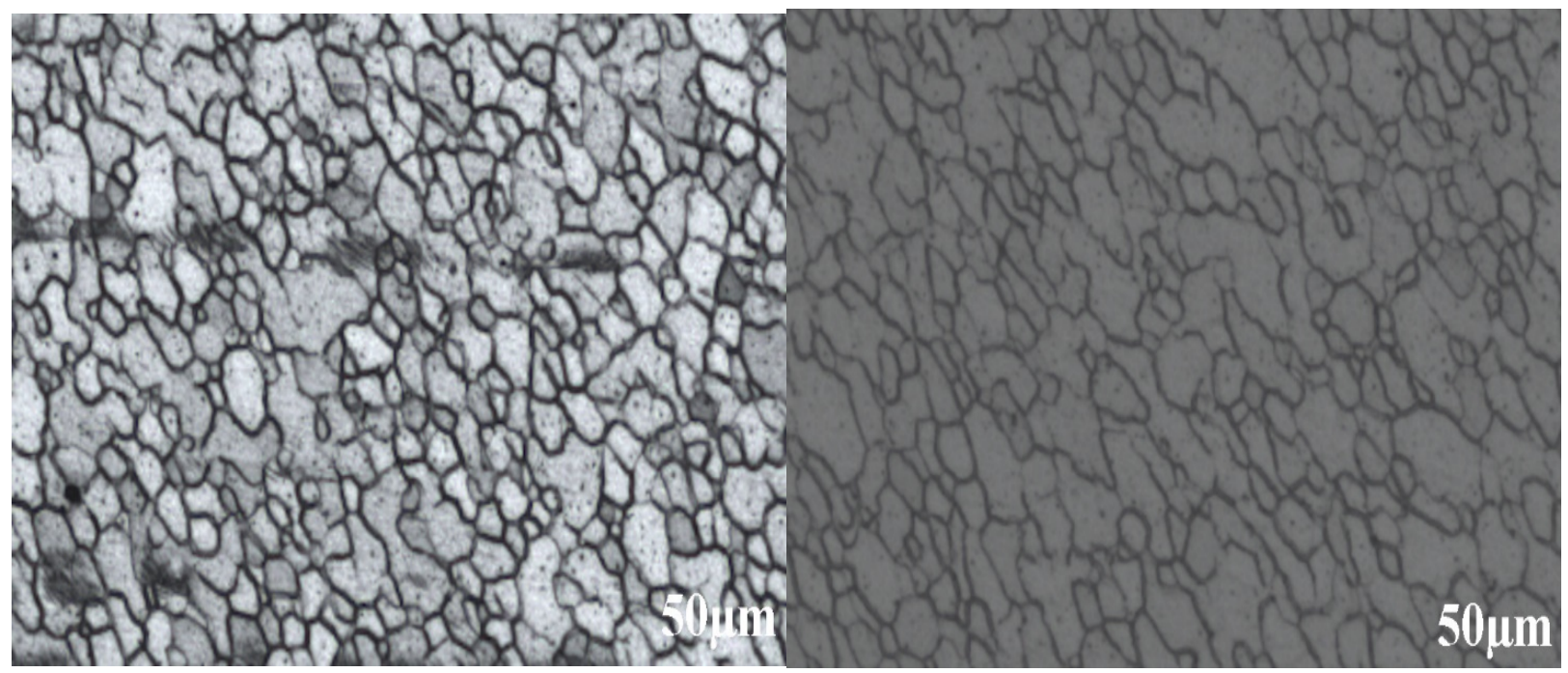

Figure 9: Microstructure of Tempered Samples at $500^{\circ} \mathrm{cFigure} 10$ : Microstructure of Tempered Samples at600 $\mathrm{c}$

The martensitic samples are then subjected to heat treatment process (tempering). The tempered sample are subjected to microstructure examination and its clearly indicates from the Figure 7, Figure 8, Figure 9 \&Figure 10 microstructure consists of fine spheroidized carbides in a ferrite matrix and carbides increase by increasing the tempering temperatures. It reduces the hardness of materials as shown in Table 4 and Graph 1.

\subsection{Hardness and Tempering Temperatures for Materials SS410 and SS420}

Table 4: Hardness Result Table for SS410 and SS420

\begin{tabular}{|l|l|l|l|l|l|l|l|}
\hline $\begin{array}{l}\text { Tempering } \\
\text { Temperature in } \mathbf{~ c}\end{array}$ & 300 & 400 & 500 & 600 & 700 & 800 \\
\hline \multirow{2}{*}{ Hardness in BHN } & SS 410 & 352 & 344 & 369 & 287 & 221 & 230 \\
\cline { 2 - 8 } & SS 420 & 430 & 420 & 450 & 350 & 270 & 280 \\
\hline
\end{tabular}




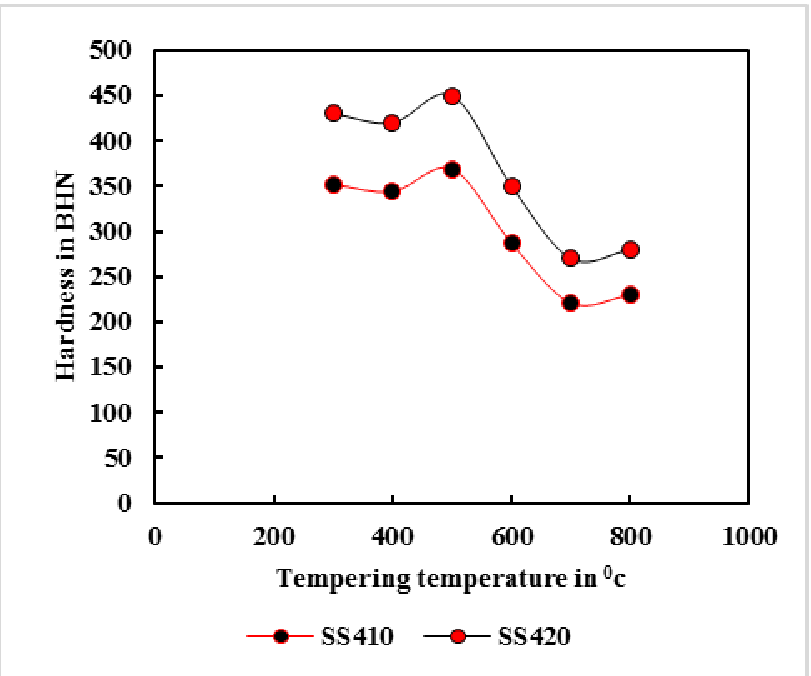

\section{Graph 1: Hardness\&Tempering Temperature for Materials SS410 \& SS420}

The hardness of both SS410 and SS420 vary almost in the same fashion. As we increase the temperature from $300^{\circ} \mathrm{c}$ to $400^{\circ} \mathrm{c}$ this region being the recovery stage no significant atomic movements is observed. Then increase the temperature to $500^{\circ} \mathrm{c}$ the hardness of both materials reach its peak values Table 4andGraph 1 . The reason behind this is the phenomenon called "Tempered Brittleness" due to which the material becomes very hard. Further, increasing the tempering temperature shows a significant decrease in their hardness values. At high temperatures, the harness starts decreasing and reaches an optimum value at $700^{\circ} \mathrm{c}$. Among these two the values of SS420 is more having more carbon content than SS410.

\subsection{Ultimate Tensile Strength for Materials SS410 and SS420}

Table 5: Ultimate Tensile Strength Materials SS410 \& SS420

\begin{tabular}{|l|l|c|c|c|c|c|c|}
\hline $\begin{array}{l}\text { Tempering } \\
\text { Temperature in } \mathbf{c}\end{array}$ & 300 & 400 & 500 & 600 & 700 & 800 \\
\hline \multirow{2}{*}{ UTS in N/mm } & SS 410 & 1246 & 1245 & 1292 & 1240 & 651.55 & 583.8 \\
\cline { 2 - 8 } & SS 420 & 1520 & 1500 & 1520 & 1550 & 785 & 695 \\
\hline
\end{tabular}

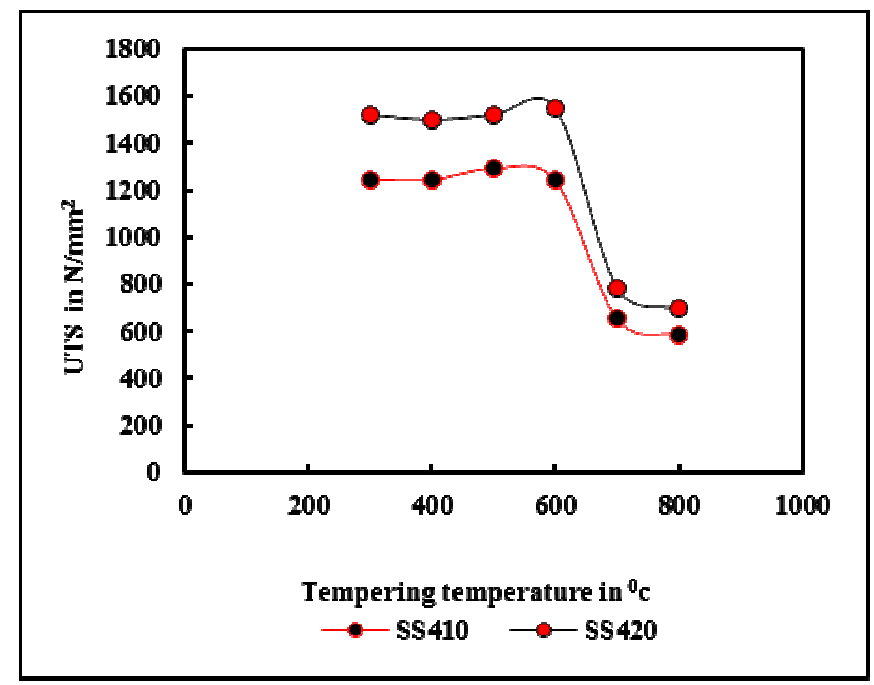

Graph 2: Ultimate Tensile Strength \&Tempering Temperature for Materials SS410 \& SS420 
The Ultimate tensile strength of SS410 shows almost constant values until $500^{\circ} \mathrm{c}$ so are the values of SS420 because of negligible atomic movements. The ultimate tensile strength depends on the hardness of the material and varies accordingly in Table 5. As soon as the temperature increases, the carbon present in the martensite starts coming out to form temper carbon which is combined with the ferrite called sorbite. This structure provides good ductility in the material by relieving the hardness and residual stresses present in the material and decreases. The steep decrease in Graph 2, Figure 7 \& Figure 8 shows the sorbite formation which is soft in nature and has low UTS and hardness. Among the two types, SS420 values are always greater than the other one because of the carbon content is more.

\subsection{Yield Strength Materials for SS410 and SS420}

Table 6: Yield Strength Result Table for SS410 and SS420

\begin{tabular}{|l|l|l|l|l|l|l|l|}
\hline $\begin{array}{l}\text { Tempering } \\
\text { Temperature in } \mathbf{~ c ~}\end{array}$ & 300 & 400 & 500 & 600 & 700 & 800 \\
\hline Yield Strength in N/mm ${ }^{2}$ & SS 410 & 1009 & 1009 & 1053 & 1075 & 542.7 & 385.4 \\
\cline { 2 - 8 } & SS 420 & 1230 & 1230 & 1270 & 1280 & 670 & 470 \\
\hline
\end{tabular}

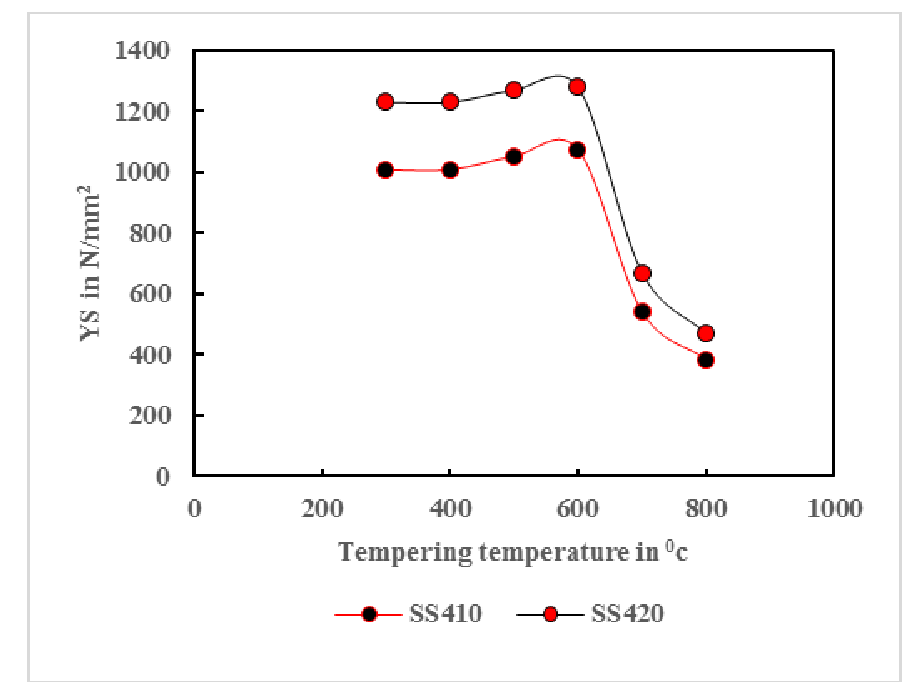

Graph 3: Yield Strength \& Tempering Temperature for Materials SS410 \& SS420

The Yield Strength of these materials increases up to $500^{\circ} \mathrm{c}$ and then suddenly decreases. This is because of the change in phase from martensite to sorbite Table 6 \& Graph 3.

\subsection{Percentage Reduction in Area of Materials SS410 and SS420}

Table 7: \% Reduction in Area Result Table for SS410 and SS420.

\begin{tabular}{|l|l|l|l|l|l|l|l|}
\hline $\begin{array}{l}\text { Tempering } \\
\text { Temperature in } \mathbf{~ c ~}\end{array}$ & 300 & 400 & 500 & 600 & 700 & 800 \\
\hline Reduction Area in \% & SS 410 & 40 & 43.5 & 41 & 47 & 55 & 49 \\
\cline { 2 - 9 } & SS 420 & 47 & 50 & 48 & 55 & 65 & 58 \\
\hline
\end{tabular}




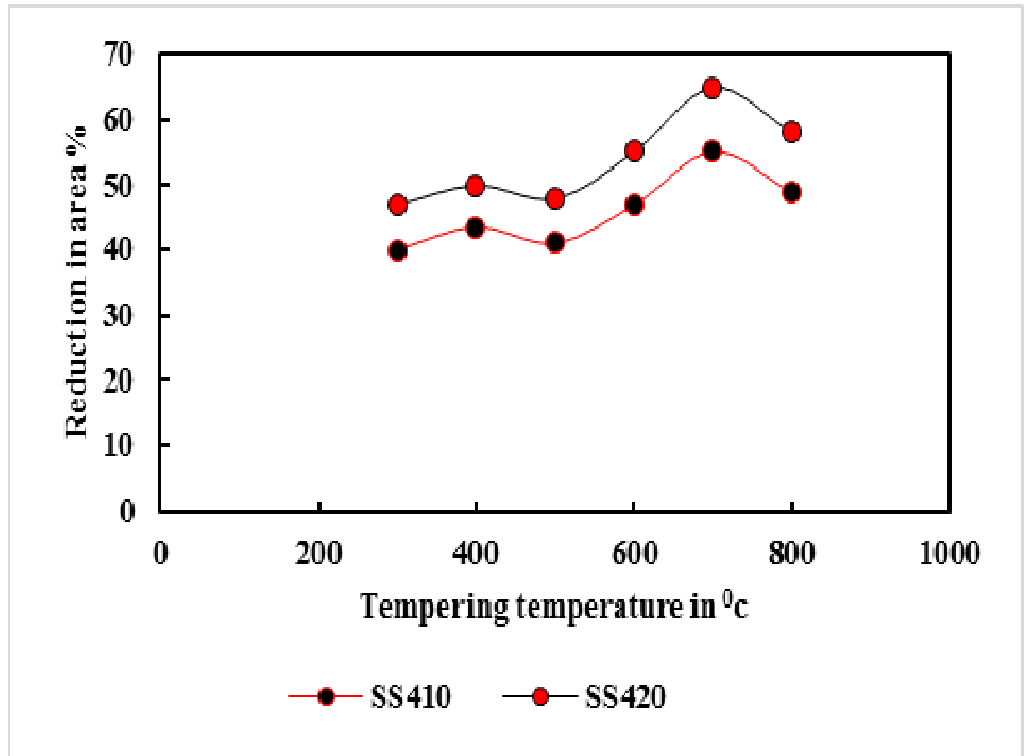

Graph 4: \% Reduction in Area \&Tempering Temperature for Materials SS410 \& SS420

This property is inversely proportional to the above mentioned ones. In the elastic region, because of ductility, the reduction increases and at $500^{\circ} \mathrm{c}$ the value decreases because of tempered brittleness and above that temperature, the materials start losing its brittleness and this value increases until the point where it reaches its maximum value at UTS and then it reduces to the point of fracture Table $7 \&$ Graph 4 where it breaks. Among SS410 and SS420 the latter has greater values than the former.

\subsection{Charpy Energy of Materials SS410 and SS420}

Table 8: CharpyResult Table for SS410 and SS420

\begin{tabular}{|l|c|c|c|c|c|c|c|}
\hline $\begin{array}{l}\text { Tempering } \\
\text { Temperature in }{ }^{0} \mathbf{c}\end{array}$ & 300 & 400 & 500 & 600 & 700 & 800 \\
\hline Impact Energy in kg & SS 410 & 4.25 & 4.3 & 3.4 & 5.6 & 11.8 & 13.2 \\
\cline { 2 - 9 } & SS 420 & 5 & 5 & 4 & 6.5 & 13 & 15 \\
\hline
\end{tabular}

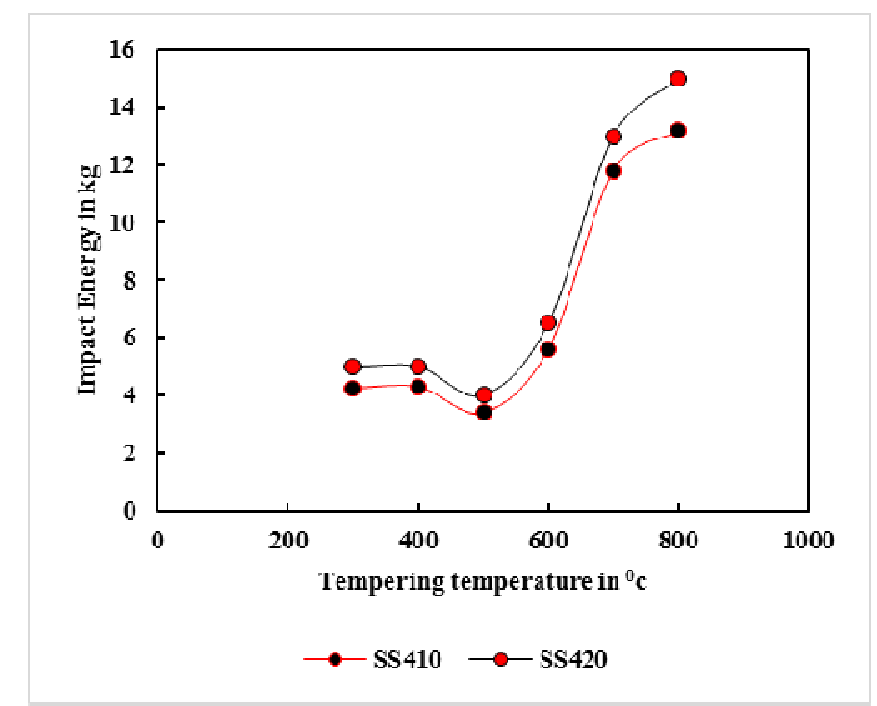

Graph 5: Impact Energy \&Tempering Temperature for Materials SS410 \& SS420 
The impact strength of both the materials increases with an increase in tempering temperature $500^{\circ} \mathrm{c}$ being an exception because of an increase in brittleness. The material hardness decreases as soon as tempering temperature increases. It also increases the impact strength value. The maximum value of impact strength is at $800^{\circ} \mathrm{c}$ where the brittleness is minimum. The value of impact strength for both the types of material is nearly the same SS420 having a little bit of greater ones Table $8 \&$ Graph 5 .

\section{$3.7 \%$ Reduction in length of Material SS410 and SS420}

Table 9: \% Elongation Result Table for SS410 and SS420

\begin{tabular}{|l|l|l|l|l|l|l|l|}
\hline $\begin{array}{l}\text { Tempering } \\
\text { Temperature in 0c }\end{array}$ & 300 & 400 & 500 & 600 & 700 & 800 \\
\hline Reduction in Length \% & SS 410 & 2.25 & 2.6 & 3.4 & 4.4 & 6.1 & 5.1 \\
\cline { 2 - 9 } & SS 420 & 2.5 & 3 & 4 & 5 & 7 & 6 \\
\hline
\end{tabular}

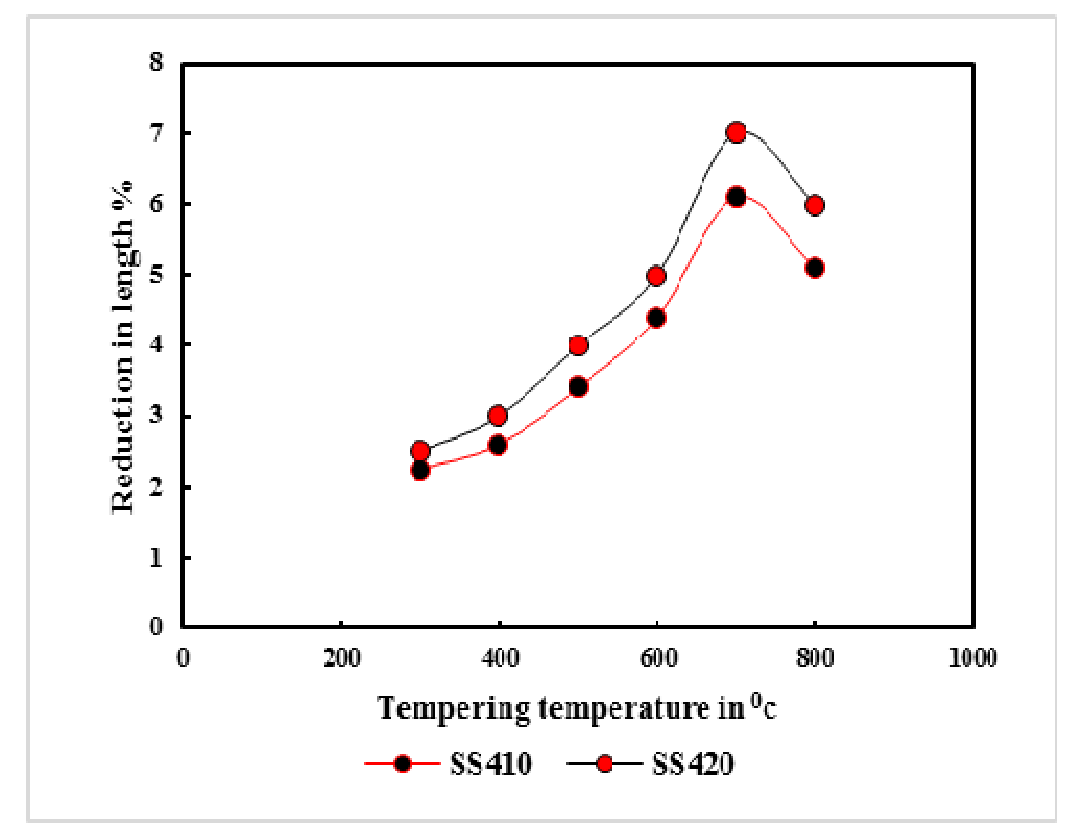

Graph 6: \% Reduction in Length \&Tempering Temperature for Materials SS410 \& SS420

It has ductility but as it reaches the UTS point, the ductility decreases entering into the plastic region and from the UTS point, the same starts decreasing as it forwards to the fracture point. Until the UTS point the elongation continues and necking appears to be happening and after UTS and recrystallization temperature $\left(720^{\circ} \mathrm{c}\right)$, the bonds starts breaking and fracture occurs. The elongation is more among SS420 than in SS410 Table 9 \& Graph 6.

\section{CONCLUSIONS}

The results of the experiments showed that as we increase the tempering temperature, there is a certain region where the hardness of the material reaches its peak value. This is because of the phenomenon called 'Tempered Brittleness', due to which the material becomes very brittle. Further increasing the temperature will gradually decrease the hardness. So for SS410 and SS420, this region being around $500^{\circ} \mathrm{c}$ it should be avoided and the temperatures for tempering should be chosen accordingly.

For different applications the properties needed from these materials are also different, to attain that, one can only alter them using different heat treatment processes and among these processes tempering is the only process through which 
we can impart impact strength to the material.

\section{REFERENCES}

1. Lee WS, Su TT, "Mechanical properties and microstructural features of AISI 4340 high-strength alloy steel under quenched and tempered conditions", Journal of Materials Processing Technology, 1999; 87(1-3):198-206.

2. Bakri, Abdalwahid K., Kadhim F. Alsultani, And Sara K. Naif. "An Alternative Metal For Stainless Steel Used In Food Industry." International Journal Of General Engineering And Technology (Ijget) 3. 3, May 2014, 11-22

3. Zou D, Han Y, Zhang W, Fang X, "Influence of Tempering Process on Mechanical Properties of 00Cr13Ni4Mo Super martensitic Stainless Steel”, Journal of Iron and Steel Research International, 2010; 17(8):50-54.

4. Ma D, Chi H, Zhou J, Yong Q, "Microstructure and Mechanical Properties of Martensitic Stainless Steel 6Cr15MoV", Journal of Iron and Steel Research International, 2012; 19(3):56-61.

5. Mishra, Pradeep Kumar, Et Al. "An Experimental Study Of Al-6062, Stainless Steel, And Inconel-625 Using Machinability Analysis." International Journal Of Mechanical And Production Engineering Research And Development (Ijmperd) 10, Feb 2020, 28-38

6. Ennis PJ, Zielinska-Lipiec A, Wachter O, Czyrska-FilemonowiczA, "Microstructural stability and creep rupture strength of the martensitic steel P92 for advanced power plant”, ActaMaterialia, 1997; 45(12):4901-4907.

7. Mirzaee M, Momeni A, Aieni N, Keshmiri H, "Effect of quenching and tempering on microstructure and mechanical properties of 410 and $410 \mathrm{Ni}$ martensitic stainless steels", Journal of Materials Research, 2017; 32(3):687-696.

8. Sivaraman, B. "Optimization of grinding parameters in austenitic stainless steel AISI 317L usingtaguchi method." International Journal of Mechanical and Production Engineering Research and Development 8.2 (2018): 1033-1038.

9. Isfahany AN, Saghafian H, Borhani G, "The effect of heat treatment on mechanical properties and corrosion behavior of AISI420 martensitic stainless steel”, Journal of Alloys and Compounds, 2011; 509(9):3931-3936.

10. Anand L, Gurland J, "Effect of internal boundaries on the yield strengths of spheroidized steels", Metallurgical Transactions A. 1976; 7(2):191-197.

11. Ma XP, Wang LJ, Liu CM, Subramanian SV, “ Microstructure and properties of 13Cr5Ni1Mo0.025Nb0.09V0.06N super martensitic stainless steel”, Materials Science and Engineering: A. 2012; 539:271-279.

12. Qin B, Wang ZY, Sun QS, "Effect of tempering temperature on properties of 00Cr16Ni5Mo stainless steel", Materials Characterization, 2008; 59(8):1096-1100.

13. Jena PK, Mishra B, Ramesh Babu M, et al. "Effect of heat treatment on mechanical and ballistic properties of a high strength armour steel”, International Journal of Impact Engineering, 2010; 37(3):242-249.

14. Darwish FA, et. al, "On the tempered martensiteembrittlement in AISI 4140 low alloy steel", Materials Science and Engineering: A. 1991; 132:5-9.

15. Zhang Z, et. al, "Microstructure evolution of hot-work tool steels during tempering and definition of a kinetic law based on hardness measurements", Materials Science and Engineering: A. 2004; 380(1-2):222-230.

16. Conde A, et. al, "Corrosion behavior of steels after laser surface melting”, Materials \& Design, 2000; 21(5):441-445.

17. JEEWG, MUHSIN J., ABDAL-KAREEM F. HASSAN, and JAWAD K. ZEBOON. "Experimental and numerical investigation of the dynamic characteristic of laminated composite plate hybrid with steel." Int. J. of General Eng. and Techn.(IJGET) 3 (2014): 1 . 
18. Rajasekhar A, Reddy GM, Mohandas T, Murti VSR, "Influence of austenitizing temperature on microstructure and mechanical properties of AISI 431 martensitic stainless steel electron beam welds", Materials \& Design, 2009; 30(5):1612-1624. 